\title{
Subjective scoring of cough in children: parent-completed vs child-completed diary cards vs an objective method
}

\author{
A.B. Chang*, R.G. Newman**, J.B. Carlin+, P.D. Phelan++, C.F. Robertson*
}

Subjective scoring of cough in children: parent-completed vs child-completed diary cards vs an objective method. A.B. Chang, R.G. Newman, J.B. Carlin, P.D. Phelan, C.F. Robertson. CERS Journals Ltd 1998.

ABSTRACT: Cough is often used as an outcome measure, although the reporting of cough is unreliable. Using a $24 \mathrm{~h}$ ambulatory cough meter to measure cough frequency, the aim of this study was to compare: 1) the correlation of child-completed diary cards to the objective measurement, with that of parent-completed diary cards; and 2) the visual analogue scale (VAS) to the verbal category descriptive (VCD) score.

The cough meter consisted of a previously validated Holter monitor and a cough processor. Eighty four children (39 with recurrent cough and 45 controls, aged 6-17 yrs) used a cough meter at least once. Thirty three subjects used the cough meter twice. Parents and children completed separate diary cards using the VAS and VCD scores. The strength of the relationship between the subjective scores and the objective recordings was analysed by spearman's rank correlation coefficient.

For daytime cough, child-completed diary cards and the VCD correlated better to the objective measurement than parent-completed diary cards and the VAS, respectively. In subjects that used the cough meter twice, the difference between the cough frequency correlated to the difference in the subjective scores. The confidence intervals for the correlation coefficients were wide. The agreement between the objective and subjective presence of daytime cough was good but that for night-time cough was poor.

We conclude that the severity of cough defined on diary cards may not represent cough frequency. Objective readings are first choice but currently not yet practical. The verbal category descriptive diary card completed by children and assisted by parents has the highest correlation to cough frequency measured objectively. Eur Respir J 1998; 11: 462-466.
Depts of *Thoracic Medicine, **Biomedical Engineering, +Clinical Epidemiology and Statistics, and ++Paediatrics, University of Melbourne, Royal Children's Hospital, Melbourne, Victoria 3052, Australia.

Correspondence: A. Chang

Dept of Respiratory Medicine

Mater Misericordiae Children's Hospital

South Brisbane

Queensland 4101

Australia

Fax: 61738408366

Keywords: Cough

cough meter

score

Received: April 171997

Accepted after revision September 111997

ABC is supported by the National Health and Medical Research Council (Australia).
The symptom of cough is widely used in research as an outcome measure in clinical studies both in children [1-3] and adults [4]. However, the reporting of nocturnal cough has been shown to be unreliable [5-7], and McKenzIe [8] has suggested that night-time cough be removed from children's diaries. In adults, the reporting of respiratory symptoms has also been shown to be significantly influenced by the psychological status of the subjects $[9,10]$. Currently, no validated scoring system for cough is available in children. Studies using cough as an outcome measure have used various subjective scoring systems, including the visual analogue scale (VAS) [1] and a variety of verbal category descriptive (VCD) scores [5, 7, 11]. Traditionally, in studies on children, questionnaires $[12,13]$ and diary cards are kept by parents [2, 5], although a recent study ut-ilized child-completed daily respiratory scores with parental ass-istance [14]. In quality-of-life questionnaires, there is an increasing trend for children to fill in their own questionnaires [12, 15], as child-completed responses have been shown to be significantly different to those completed by parents [16].

The Brompton group, who first described the innovative ambulatory cough meter $[7,17]$ for the objective measurement of the frequency of cough, raised the standard of assessing cough. Using similar preprocessing of signals utilized by $\mathrm{Hsu}$ et al. [7], we recently developed a less expensive ambulatory cough meter by adapting a disused Holter monitor [18]. Using our cough meter for the objective measurement of the frequency of cough, the aim of this study was to compare: 1) the correlation of child-completed diary cards to the objective measurement, with that of parent-completed diary cards; and 2) the VAS to the VCD.

\section{Materials and methods}

\section{Subjects}

Children with nonspecific recurrent cough ( $\check{S} 2$ episodes of cough, each lasting $\breve{S} 2$ weeks in the last 12 months) were recruited from the out-patients department. Children without a history of recurrent cough were enrolled as controls in the same season. The children were examined by a paediatrician $(\mathrm{ABC})$, and spirometry was performed (Jaeger box, Wuerzburg, Germany) in the sitting position with use of a noseclip. The exclusion criteria included: moist cough; 
abnormal chest examination; abnormal chest radiograph; or reduced spirometry (forced expiratory volume in one second (FEV1) or forced vital capacity (FVC) $<85 \%$ of predicted).

Formal consent was obtained, and the study was approved by the hospital's Ethics Committee on Human Research.

\section{Study design}

All the children used an ambulatory cough meter for 24 $\mathrm{h}$ per occasion. The children were encouraged to participate in their usual non-water-based activities. The subjects were studied on two occasions, 7-10 days apart, during a coughing period, and the controls used the cough meter once. The parent(s) and child were given a colour-coded chart, which consisted of two cough-scoring systems, the VAS and the VCD score, which were completed daily based on the severity of the child's cough. The parent(s) were requested to complete their diary card first and then to remind and, if necessary, assist the child to complete the child's card, on both scoring systems.

\section{The subjective count score chart}

The VAS is a vertically marked scale of 1 to 10 , with 10 representing the presence of the most severe cough and 1 representing the absence of cough. The VCD is a score assigned to a description for daytime and night-time cough.

Daytime score. $0=$ no cough; $1=$ cough for one or two short periods only; 2 = cough for more than two short periods; 3 = frequent coughing but does not interfere with school or other activities; $4=$ frequent coughing which interferes with school or other activities; and $5=$ cannot perform most usual activities due to severe coughing.

Night-time score. $0=$ no cough at night; $1 \mathrm{a}=$ cough on waking only; $1 \mathrm{~b}=$ cough on going to sleep only; $2=$ awoken once or awoken early due to coughing; $3=$ frequent waking due to coughing; $4=$ frequent coughs most of the night; and $5=$ distressing cough.

\section{The cough meter}

An ambulatory cough meter, which consisted of a Holter monitor and a cough processor, was developed and validated [18]. The total weight of the cough meter was $588 \mathrm{~g}$. It had four attachment points (three electromyogram (EMG) electrodes and one microphone) and provided $24 \mathrm{~h}$ of continuous recording. The cough processor preprocesses (by filtering) the input signals (EMG and audio signals) so as to minimize unwanted signals, and then full-wave rectifies and averages (time constant $=3 \mathrm{~ms}$ ) the signals before recording onto the DMI Holter recorder (Diagnostic Medical Instruments Inc., New York, USA). The filters for the audio signal were a 4 pole high pass (HP) Butterworth filter with a $-3 \mathrm{~dB}$ point at $1,200 \mathrm{~Hz}$ and a roll-off of $24 \mathrm{~dB}$ / octave, and a 2-pole low pass (LP) filter, with the $-3 \mathrm{~dB}$ point at $5,000 \mathrm{~Hz}$ and the roll-off of $12 \mathrm{~dB}$ /octave. For the
EMG signal, the LP filter was the same as the audio system but the HP filter had a $-3 \mathrm{~dB}$ point at $200 \mathrm{~Hz}$. The cough signals were easily distinguished from signals of other activities. The recorded cough-meter tapes were replayed on the cardioview monitor (DMI, New York, USA) and the coughs counted by the same investigator who was blinded to the tapes. All tapes were processed before the subjective diary-cards were available. The onset of sleep was taken when there was cessation of activity, which was easily seen.

\section{Statistical analysis}

Spearman's rank correlation $\left(\mathrm{r}_{\mathrm{s}}\right)$ was used to assess the association between variables, and the $95 \%$ confidence interval $(95 \% \mathrm{CI})$ was calculated with $\mathrm{z}$ transformation and back transformed [19]. Cohen's Kappa [20] (agreement adjusted for chance) was used to assess agreement between the report of daytime (VCD score $\breve{S} 1$ ) and nighttime cough (VCD score $\breve{S} 2$ ) and that detected by the cough meter. Paired Wilcoxon test was used for the comparison of responses between parent and child-completed diary cards. The Statistical Package for the Social Sciences (SPSS)® (version 6.0) statistical software package was utilized. A p-value of less than 0.05 was taken as statistically significant.

\section{Results}

Thirty nine subjects (18 males and 21 females; median age 9.4 yrs, range $6-17$ yrs) and 45 controls ( 22 males and 23 females; median age 9.6 yrs, range 6-17 yrs) were enrolled. There was no difference in age between the groups. Sixteen children were aged 6-7 yrs. Two subjects, both aged 6 yrs, could not tolerate the cough meter (itch at the site of EMG electrodes) and the microphone dislodged in a control child, rendering the cough meter assessment inadequate in three children. The cough diary cards (child or parents') were incomplete in either the VAS or VCD in five children (two subjects and three controls). A child (control) and parent did not return the diary card and a 6 yr old subject was unable to complete the diary card. Incomplete data were excluded from the analysis. The median number of coughs in the subjects was 61 coughs per $24 \mathrm{~h}$ (interquartile range (IQR) 159) and 2.5 per night (IQR 20), and that of the controls was 10 (IQR 15) and 0 (IQR 2.7), respectively.

The agreement adjusted for chance (Cohen's Kappa) bet-ween the subjective and objective presence of daytime cough for the subjects was $100 \%$ (kappa values cannot be calculated), and that for the controls was 0.61 for childcompleted cards and 0.44 for parent-completed cards. When both groups were considered together, the agreement was 0.67 and 0.49 , respectively. For night-time cough, the agreement between the subjective and objective presence of cough was poor both in subjects and controls (table 1), even when cough on going to sleep or waking only (score $1 \mathrm{a}$ and $1 \mathrm{~b}$ ) was excluded. The agreement values were again higher for child-completed diary cards than parent-completed cards both for subjects and controls. 
Table 1. - Comparison of parent- and child-completed diary scores with cough frequency measured on the cough meter

\begin{tabular}{|c|c|c|c|c|c|c|c|c|}
\hline & \multirow[t]{2}{*}{ Score type } & \multirow{2}{*}{$\begin{array}{c}\text { Subjects } \\
\mathrm{n}\end{array}$} & \multicolumn{3}{|c|}{ Parent-completed diary } & \multicolumn{3}{|c|}{ Child-completed diary } \\
\hline & & & $r_{s}$ & $(95 \% \mathrm{CI})$ & p-value $\#$ & $r_{s}$ & $(95 \% \mathrm{CI})$ & $\mathrm{p}$-value $\#$ \\
\hline \multirow{5}{*}{ Subjects } & VAS & 36 & 0.51 & $(0.21-0.72)$ & 0.002 & 0.55 & $(0.27-0.74)$ & 0.001 \\
\hline & Day-VCD & 35 & 0.58 & $(0.21-0.76)$ & 0.00001 & 0.63 & $(0.37-0.79)$ & 0.00001 \\
\hline & Night-VCD & 35 & 0.44 & $(0.13-0.68)$ & 0.008 & 0.52 & $(0.22-0.73)$ & 0.001 \\
\hline & Diff-VAS & 33 & 0.41 & $(0.11-0.71)$ & 0.028 & 0.44 & $(0.11-0.68)$ & 0.011 \\
\hline & Diff-VCD & 33 & 0.46 & $(0.03-0.68)$ & 0.013 & 0.50 & $(0.19-0.72)$ & 0.003 \\
\hline \multirow[t]{4}{*}{ Controls } & VAS & 43 & 0.40 & $(0.11-0.62)$ & 0.008 & 0.47 & $(0.20-0.68)$ & 0.001 \\
\hline & Day-VCD & 40 & 0.52 & $(0.25-0.71)$ & 0.001 & 0.65 & $(0.42-0.80)$ & 0.00001 \\
\hline & Night-VCD & 40 & 0.20 & $(-0.11-0.48)$ & 0.21 & 0.38 & $(0.08-0.62)$ & 0.015 \\
\hline & & & & \multicolumn{5}{|c|}{ Cohen's Kappa value* } \\
\hline \multirow[t]{2}{*}{ All } & Day & 75 & & 0.49 & & & 0.67 & \\
\hline & Night & 75 & & 0.17 & & & 0.3 & \\
\hline \multirow[t]{2}{*}{ Subjects } & Day & 35 & & + & & & + & \\
\hline & Night & 35 & & 0.11 & & & 0.22 & \\
\hline \multirow[t]{2}{*}{ Controls } & Day & & & 0.44 & & & 0.61 & \\
\hline & Night & 40 & & 0.16 & & & 0.24 & \\
\hline
\end{tabular}

VAS: visual analogue scale; VCD: verbal category descriptive score; Diff-VAS: correlation between the difference of VAS scores to the difference of cough frequency of the two occasions; Diff-VCD: correlation between the difference of VCD scores to the difference of cough frequency of the two occasions; 95\% CI: 95\% confidence interval. *: two-tailed p-value of Spearman's correlation; *: agreement between subjective and objective presence of cough. $+: 100 \%$ agreement - Kappa value cannot be calculated.

a)

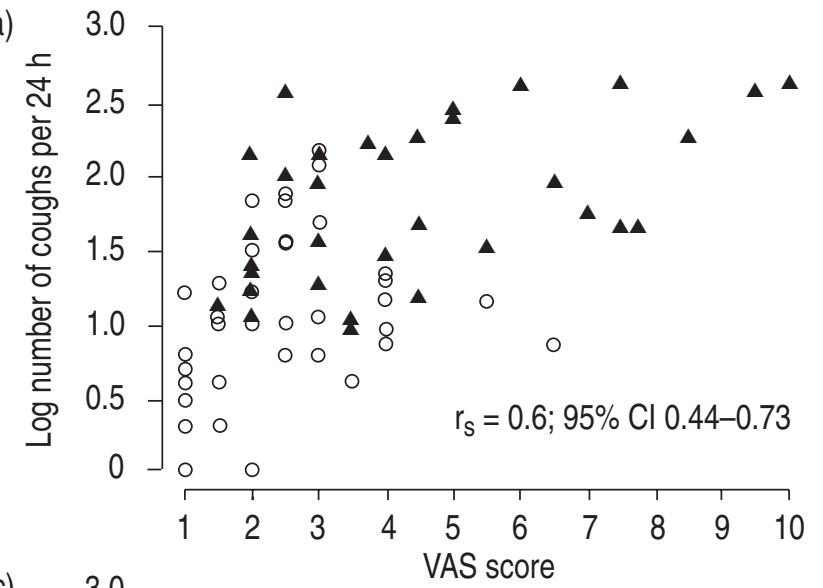

c)

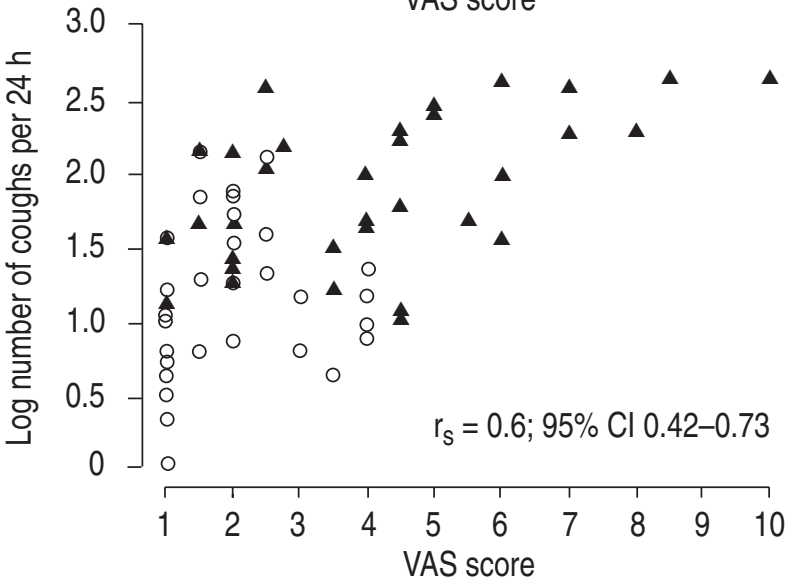

b)

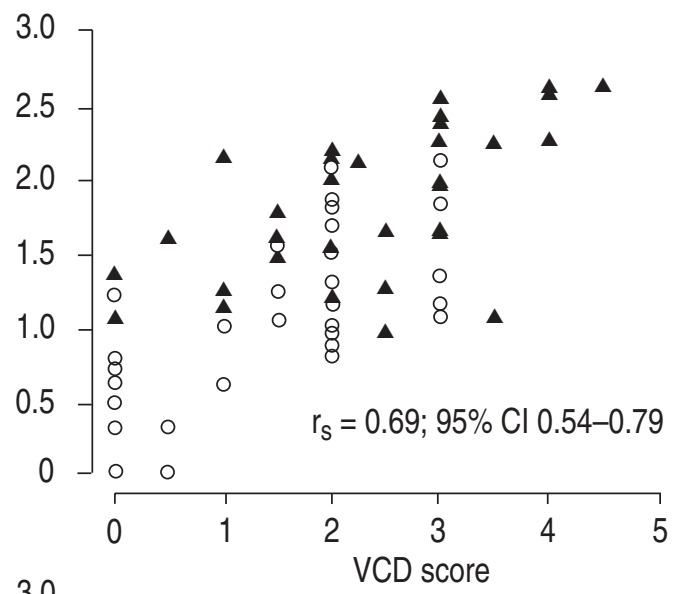

d)

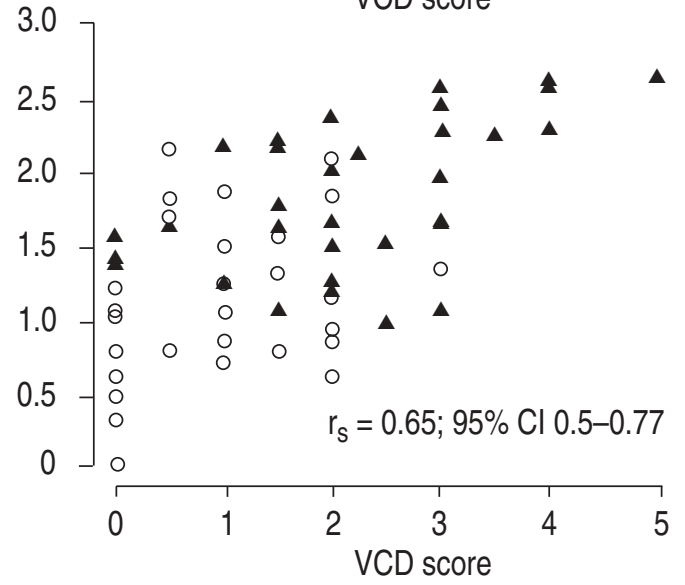

Fig. 1. - Spearman's correlation $\left(\mathrm{r}_{\mathrm{s}}\right.$ ) between the frequency of cough measured by the cough meter (coughs in $24 \mathrm{~h}$ period) $v s$ the visual analogue scale (VAS) and the verbal category descriptive (VCD) score as recorded by the child and the parent of the subjects $(\mathbf{\Delta})$ and controls (O). a) VAS score, childcompleted diary; b) VCD score, child-completed diary; c) VAS score, parent-completed diary; d) VCD score, parent-completed diary. 95\% CI: 95\% confidence interval. The $\mathrm{r}_{\mathrm{s}}$-values in these figures are calculated for the entire group, whereas those in table 1 represent the correlation for the subdivided group. 
Table 2. - Comparison of parent-completed and childcompleted cough diary scores

\begin{tabular}{lcccccc}
\hline \multirow{7}{*}{ Subjects } & & & \multicolumn{3}{c}{ Diary scores } & \\
\cline { 5 - 6 } & Score & Subjects & $\begin{array}{c}\text { Parent- } \\
\text { completed }\end{array}$ & $\begin{array}{c}\text { Child- } \\
\text { completed }\end{array}$ & p-value\# \\
& VAS & 36 & 4 & $(3)$ & $3.5(3.2)$ & 0.42 \\
& VCD & 37 & 2 & $(1.5)$ & $2(1.5)$ & 1 \\
& Night & 37 & 1 & $(2)$ & $1(2)$ & 1 \\
Controls & VAS & 42 & 1 & $(1)$ & $2(2)$ & 0.0001 \\
& VCD & 43 & 0 & $(1)$ & $1(2)$ & 0.0009 \\
& Night & 41 & 0 & $(0)$ & $0(1)$ & 0.04 \\
\hline
\end{tabular}

Values are presented as median, and interquartile range in parenthesis. VAS: visual analogue scale; VCD: verbal category descriptive score. \#: p-value (Wilcoxon test) comparing the scores on parent and child-completed diary cards.

Although all (except parent-completed night-time VCD) scores correlated to the cough meter counts, the confidence intervals were very wide (table 1). The correlation coefficients $\left(r_{s}\right)$ for child-completed diaries were consistently higher than those for parent-completed diaries in the subjects and controls for both scores (fig. 1 and table 1). However, the difference between the $r_{s}$ value of the childcompleted $v s$ parent completed was small. The VCD had a higher correlation to the objective measure than the VAS both in the subjects and controls, for parent's and childcompleted diaries. In the subjects, there was no difference between the parent and child scores both in the VCD and VAS. In the controls, the severity of the cough scores was significantly higher in the child-completed cards than the parent-completed cards (table 2).

In subjects who used the cough meter on two occasions $(n=33)$, the difference in subjective scores correlated to the difference in cough frequency of the two occasions (table 1). However, the confidence intervals for the correlation coefficient were again very wide.

\section{Discussion}

In this study comparing the severity of cough measured objectively by an ambulatory cough meter to two subjective cough diary scoring systems, completed by parents and children, we found that the subjective scoring method with the highest correlation to the objective measure was the VCD score completed by children. However, in general, the subjective reporting of cough is variable and nighttime reporting of cough is unreliable.

Although there was a correlation between the subjective and objectives scores, the confidence intervals were very wide, especially for parent-completed cards and for the VAS. Correlation coefficient is not the correct statistical method of assessing agreement between two methods of clinical measurement [21]. However, the method of BLAND and Altman [21] was not used, as we were comparing the strength of the relationship between the subjective and objective scores and not the agreement between two objective methods.

The unreliability of the reporting of nocturnal cough found in the present study, which not only included children with recurrent cough but also children without troublesome cough, is similar to that described previously [5, 6]. Archer and Simpson [5] and Falconer et al. [6] studied chil- dren with asthma and nocturnal cough and found poor agreement between the objective and subjective presence of nocturnal cough as reported by children [6] or parents [5]. At the present time, there have been no studies on the reliability of the subjective reporting of daytime cough in children. Hsu et al. [7] found a correlation between the subjective reporting of daytime cough and the frequency of cough in adults, but the agreement between the objective and subjective presence of daytime cough was not mentioned. MunYard and Bush [17] did not report on the agreement of the cough question completed by parents and that recorded on the cough meter of the 41 "normal" children studied. We have shown that the agreement between the subjective reporting and the objective presence of daytime cough was excellent in children who had troublesome cough. In the control group, the agreement was only good in child-completed diary cards. As the children in the present study were Š 6 yrs of age and spent a significant part of the day in school, this finding is not surprising. We compared child-completed and parent-completed cards as there is currently no standard method in the subjective reporting of cough. Studies using diary cards completed by parents $[2,11]$ and children $[14,22]$ have been reported. Other studies did not clearly specify who completed the diary cards $[3,23]$. Both for the VCD and VAS, and both in subjects and controls, the correlation of the subjective score to the objective measurement was consistently higher in the child-completed cards than the parent-completed diaries. The difference was small in the subjects but more marked in the control group. In studies of children, questionnaires are traditionally completed by parents but there is an increasing trend for children to complete their own questionnaires as the child's perception of their own condition can be different to that of the parents [12].

A variety of cough-scoring systems $[1,5,7,11]$ have been used for the assessment of cough. There have been no studies comparing the VAS to the VCD for the assessment of cough severity. SLY et al. [22] compared these two subjective scores recorded in child-completed diary cards in the assessment of the severity of asthma, and found no correlation between either score and FEV1. The use of the VAS is popular, especially in studies on the perception of pain [24]. Although the VAS is conceptually an easier system to use, this study has shown that it has a poorer correlation to the objective measurement of cough when compared to the VCD both in parent and child-completed diary cards.

This and other studies [5, 7] comparing objective and subjective scores for cough assume that subjects and parents judge the severity of cough on the frequency of cough. However, it is possible that some parents may assess the severity of cough on the length of the paroxysms or the loudness of the cough, which would not necessarily correlate to the frequency of cough. Although the frequency of cough is forseeably the only objective ambulatory measurement available, we suggest that the severity of cough as defined on diary cards is not interchangeable with the frequency of cough. Perhaps it is analogous to the measurement of FEV1 as a measurement of the severity of asthma.

The use of an ambulatory cough meter is largely limited to research for several reasons. Apart from its expense (cost of Holter monitor and cough processor is approximately A $\$ 3,800$ (US $\$ 2,500)$ ), and the training and time 
required to read the tape, tolerance of the ambulatory cough meter was an issue in the younger children. The two children who could not tolerate the cough meter represented $12 \%$ of children aged 6-7 yrs in this study. Although the children were encouraged to participate in all non-waterbased activities, we did not assess how frequently normal activities were maintained whilst the cough meter was in use. However, many of the control children were enrolled from a school and, in these children, their usual nonwater-based sporting activities occurred.

From our data, we suggest that, because cough is unreliably reported, clinical trials that use cough as an outcome measure should be interpreted with caution. Perhaps, interventions for the symptom of nocturnal cough alone obtained solely on subjective reports, should not be initiated until an objective measure can be obtained. Although it would be ideal to use an ambulatory cough meter to assess the severity of cough in all research clinical studies, this is currently not yet practical. Until the ideal situation arises, we conclude that the severity of cough defined on diary cards may not represent the frequency of cough measured objectively. The difference in parent-completed vs child-completed diary cards is small in subjects and moderate in controls. Nevertheless, the most valid subjective method of scoring cough in children over 6 yrs of age is the verbal category score completed by children with parental assistance. We also support the opinion of other authors $[5,6,8]$ that night-time diary cards should not be used, as it is not only unvalidated but it has been repeatedly shown to be unreliable.

\section{References}

1. Llangovan P, Pedersen S, Godfrey S, Nikander K, Niviski N, Warner JO. Treatment of severe, dependent preschool asthma with nebulised budesonide suspension. Arch Dis Child 1993; 68: 356-359.

2. van Essen-Zandviiet, Highes MD, Waalkens HJ, Duiverman EJ, Kerrebjijn KF and Dutch CNSLD study group. Remission of childhood asthma after long-term treatment with an inhaled corticosteroid (budesonide): can it be achieved? Eur Respir J 1994; 7: 63-68.

3. Konig P, Eigen H, Ellis MH, et al. The effect of nedocromil on childhood asthma during the viral season. Am J Respir Crit Care Med 1995; 152: 1879-1886.

4. North American Tilade group. A double-blind multicenter group comparative study of the efficacy and safety of nedocromil sodium in the management of asthma. Chest 1990, 97: 1299-1306.

5. Archer LN, Simpson H. Night cough counts and diarycard scores in asthma. Arch Dis Child 1985; 60: 473-474.

6. Falconer A, Oldman C, Helms P. Poor agreement between reported and recorded nocturnal cough in asthma. Pediatr Pulmonol 1993; 15: 209-211.

7. Hsu JY, Stone RA, Logan-Sinclair RB, Worsdell M, Busst CM, Chung KF. Coughing frequency in patients with persistent cough: assessment using a 24 hour ambulatory recorder. Eur Respir J 1994; 7: 1246-1253.

8. McKenzie S. Clinical features and their assessment. In: Silverman M, ed. Childhood Asthma and Other Wheezing Disorders. London, Chapman \& Hall Medical, 1995; pp. 175-200.

9. Dales RE, Spiker WO, Schecter MT, Suissa S. The influence of psychological status on respiratory symptom reporting. Am Rev Respir Dis 1989; 139: 1459-1463.

10. King B, Cotes JE. Relation of lung function and exercise capacity to mood and attitudes to health. Thorax 1989; 44: 402-409.

11. Taylor JA, Novack AH, Almquist JR, Rogers JE. Efficacy of cough suppressants in children. J Pediatr 1993; 122: 799-802.

12. Richards JM, Hemstreet MP. Measures of life quality, role performance and functional status in asthma research. Am J Respir Crit Care Med 1994; 149: S31-S39.

13. Clifford RD, Radford M, Howell JB, Holgate ST. Prevalence of respiratory symptoms among 7 and 11 year old schoolchildren and association with asthma. Arch Dis Child 1989; 64: 1118-1125.

14. Clough JB, Sly PD. Association between lower respiratory tract symptoms and falls in peak expiratory flow in children. Eur Respir J 1995, 8: 817-822.

15. West A. Methodological issues in the assessment of quality of life in childhood asthma: what educational research has to offer. In: Christie M, French D, eds. Assessment of Quality of Life in Childhood Asthma. Switzerland, Harwood Academic Publishers, 1994; pp. 121-130.

16. Juniper EF, Guyatt GH, Dolovich J. Assessment of quality of life in adolescents with allergic rhinoconjunctivitis: development and testing of a questionnaire for clinical trials. J Allergy Clin Immunol 1994; 93: 413-423.

17. Munyard P, Bush A. How much do normal children cough? Arch Dis Child 1996; 74: 531-534.

18. Chang AB, Newman R, Phelan PD, Robertson CF. A new use for an old Holter monitor: an ambulatory coughmeter. Eur Respir J 1997; 10: 1637-1639.

19. Altman DG. In: Practical Statistics for Medical Research. London, Chapman \& Hall, 1991; pp. 293-296.

20. Altman DG. In: Practical Statistics for Medical Research. London, Chapman \& Hall, 1991; pp. 403-405.

21. Bland JM, Altman DG. Statistical methods for assessing agreement between two methods of clinical measurement. Lancet 1986; 1: 307-308.

22. Sly PD, Landau LI, Weymouth R. Home recording of peak expiratory flow rates and perception of asthma. Am J Dis Child 1985; 139: 479-482.

23. Hoskyn EW, Beardsmore CS, Simpson H. Chronic night cough and asthma severity in children with stable asthma. Eur J Pediatr 1995; 154: 320-325.

24. Sims C, Johnson CM, BergesioR, Delfos SJ, Avrsamides EA. Rectal indomethacin for analgesia after appendicectomy in children. Anaesth Intensive Care 1994; 22: 272275. 